\title{
The Intestinal Parasites of King Richard III
}

Authors:

Piers D. Mitchell MD, ${ }^{1 *}$ Hui-Yuan Yeh MA, ${ }^{1}$ Jo Appleby PhD, ${ }^{2}$ Richard Buckley $B A,^{3}$

1 Division of Biological Anthropology, Department of Archaeology and Anthropology, University of Cambridge, The Henry Wellcome Building, Fitzwilliam Street, Cambridge, CB2 1QH, UK.

2 School of Archaeology and Ancient History, University of Leicester, University Road, Leicester, LE1 7RH, UK.

3 University of Leicester Archaeological Services, University of Leicester, University Road, Leicester, LE1 7RH, UK.

*Correspondiong Author: Dr. Piers Mitchell, Division of Biological Anthropology, Department of Archaeology and Anthropology, University of Cambridge, The Henry Wellcome Building, Fitzwilliam Street, Cambridge, CB2 1QH, UK. e-mail: pdm39@cam.ac.uk 


\section{The Intestinal Parasites of King Richard III}

Richard III ruled England from 1483-85 AD, and he died at the battle of Bosworth Field near Leicester. He is one of England's most well known medieval kings because of his portrayal as a villain in Shakespeare's play Richard III, in part a consequence of his usurping the throne and the perception of his spinal deformity. His body was buried in the church of the friars minor (Grey Friars) in Leicester. ${ }^{1}$ In September 2012 Richard's remains were excavated and sediment samples were taken from the sacral area of his pelvis, and control samples from his skull and the soil outside the grave cut (figure 1). Analysis was done with disaggregation with trisodium phosphate, microsieving with 300,160 , and $20 \mu \mathrm{m}$ diameter mesh, and then light microscopy. ${ }^{2}$ The results showed the presence of multiple roundworm eggs (Ascaris lumbricoides) in the sacral sample, where the intestines would have been during life (figure 2). The eggs were decorticated and dimensions ranged from 55.1-69.8 $\mu \mathrm{m}$ in length to $40.9-48.2 \mu \mathrm{m}$ in breadth. The control sample from the skull was negative for parasite eggs, and the control sample from outside the grave cut shows only scanty environmental soil contamination with parasite eggs.

These results show that Richard was infected with roundworms in his intestines. Roundworm is spread by the faecal contamination of food by dirty hands, or use of faeces as a crop fertiliser. No other species of intestinal parasite were present in the samples. Past research into human intestinal parasites in Britain was shown a number of species to have been present prior to the 
medieval period, including roundworm (Ascaris lumbricoides), whipworm (Trichuris trichiura), beef/pork tapeworm (Taenia saginata/solium), fish tapeworm (Diphyllobothrium latum), and liver fluke (Fasciola hepatica). We would expect nobles of this period to have eaten meats such as beef, pork and fish regularly, but there was no evidence for the eggs of the beef, pork or fish tapeworm. This may suggest that his food was cooked thoroughly, which would have prevented the transmission of these parasites.

Funding: University of Leicester, Richard III society, Leicester City Council, Leicester Shire Promotions, Leicester Adult Schools.

\section{References}

${ }^{1}$ Buckley R, Morris M, Appleby J, King T, O'Sullivan D, Foxhall L. 'The king in the car park': new light on the death and burial of Richard III in the Grey Friars church, Leicester in 1485. Antiquity 2013; 87: 519-38.

${ }^{2}$ Anastasiou E, Mitchell PD. Simplifying the process for extracting parasitic worm eggs from cesspool and latrine sediments: a trial comparing the efficacy of widely used techniques for disaggregation. International Journal of Paleopathology doi:10.1016/j.ijpp.2013.04.004. 


\section{List of Figures}

Figure 1: Skeleton of Richard at excavation, with sampling locations marked. s sacral sample, c1 - skull control sample, c2 - control sample from outside grave

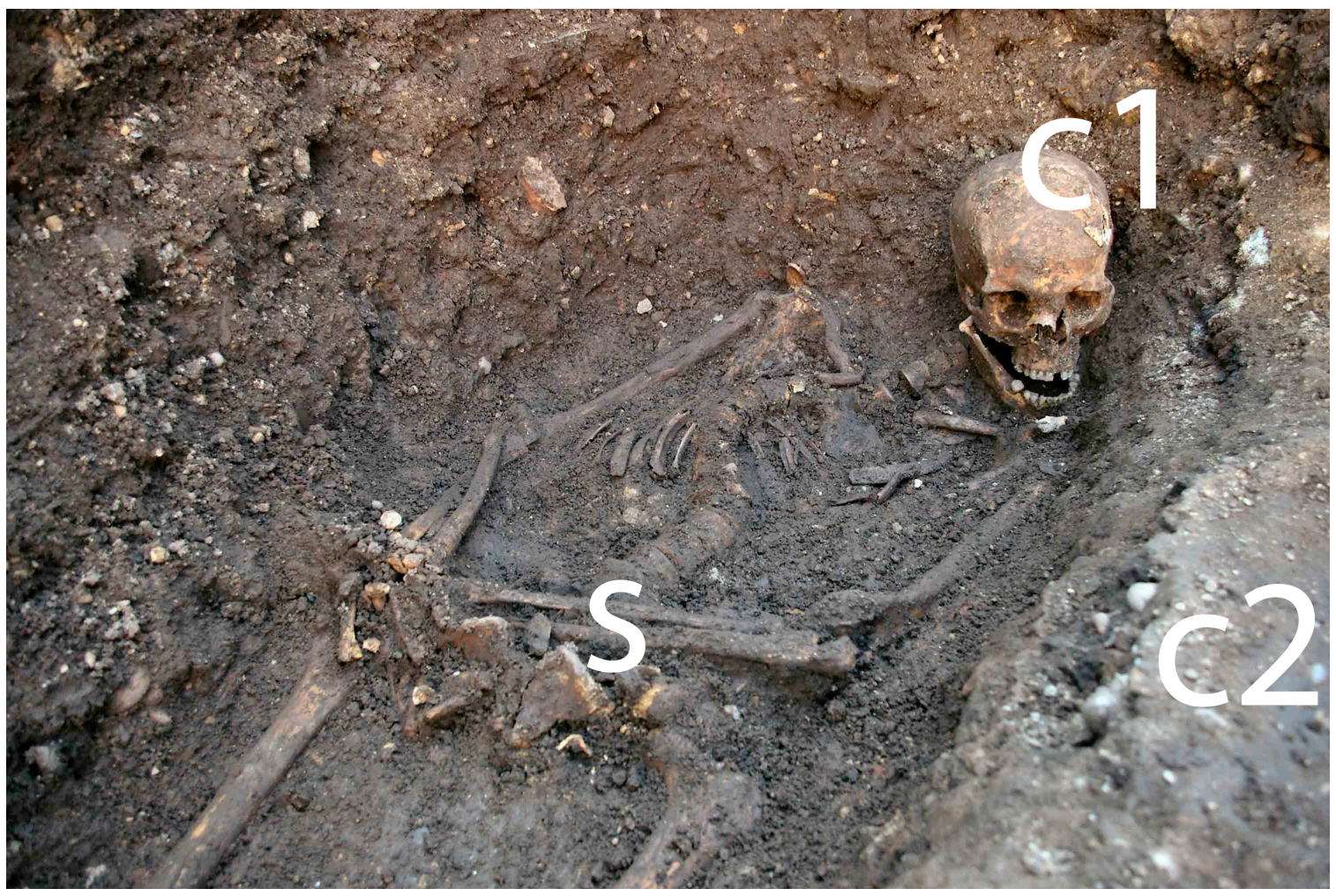


Figure 2: Decorticated roundworm egg (Ascaris lumbricoides) from sacral sample

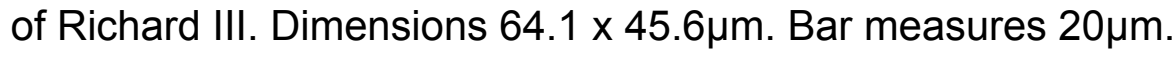

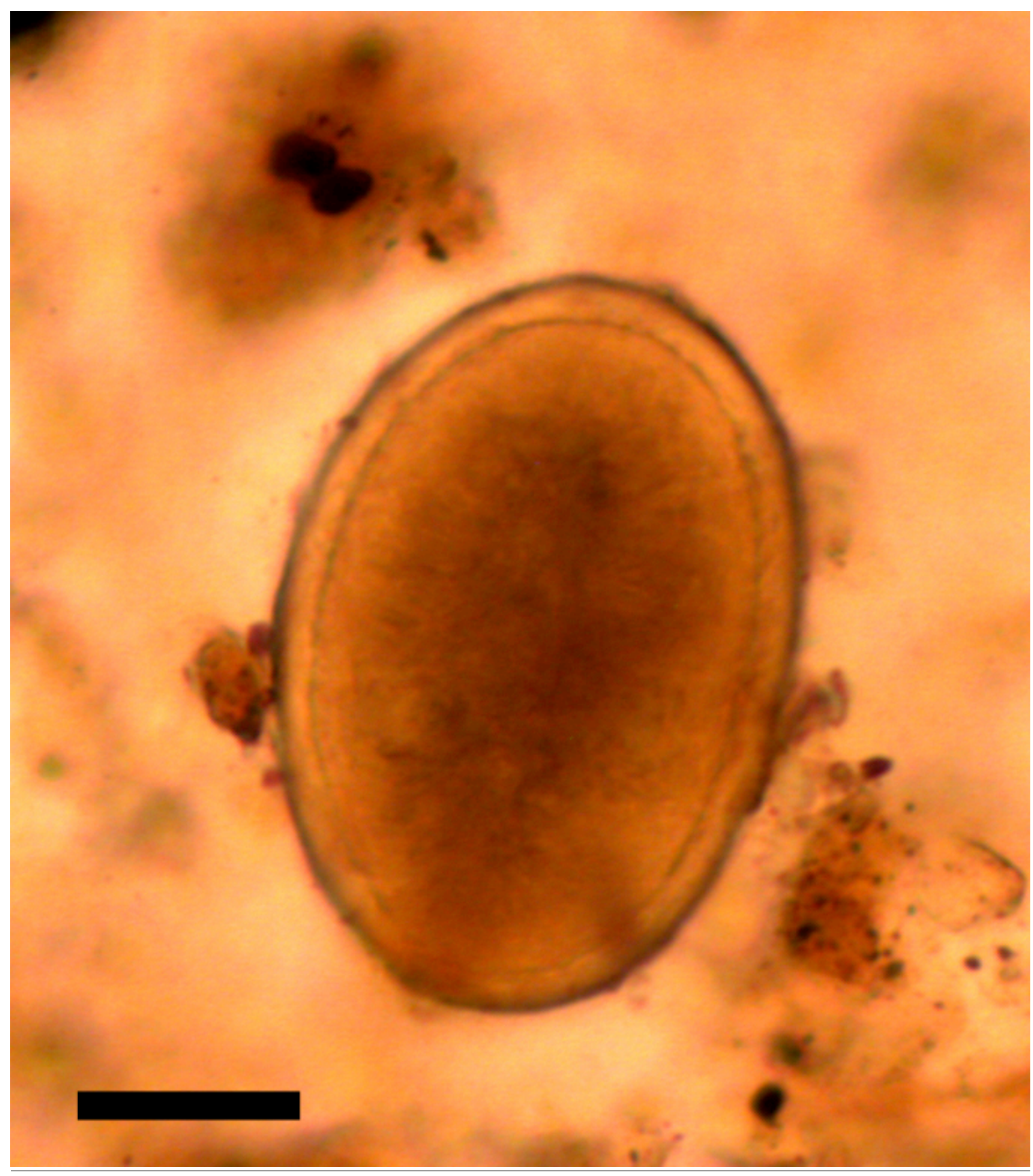




\section{Authors Contributions}

PM designed the study, performed the bulk of the parasite analysis, performed the background research and wrote the article, HYY performed some of the parasite analysis, JB excavated the skeleton and took the samples, and RB led the entire excavation project.

\section{Role of Funding Source}

The research was funded by the University of Leicester, Richard III Society, Leicester City Council, Leicester Shire Promotions, and Leicester Adult Schools. While they funded the excavations and post excavation analysis of the remains from the Grey Friars church, they had no influence on what research was undertaken, nor on the interpretation of the results from that research.

\section{Ethics Committee Approval}

No ethics committee approval was required since the study did not involve patients. The UK Minstry of Justice issued a licence permitting the excavation.

\section{Conflict of Interest Statement}

The authors have no conflict of interest to declare. 